\section{Cureus}

\title{
Systematic Review 2013: Association Between Wind Turbines and Human Distress
}

Ian Arra ${ }^{1}$, Hazel Lynn ${ }^{2}$, Kimberley Barker ${ }^{3}$, Chiebere Ogbuneke ${ }^{4}$, Sophie Regalado ${ }^{5}$

1. Public Health and Preventive Medicine, Northern Ontario Medical School- East Campus - Laurentian University, Health Sciences Education Resource Centre 2. Public Health and Preventive Medicine, Grey Bruce Health Unit, Ontario, Canada 3. Public Health and Preventive Medicine Program, Northern Ontario School of Medicine, East Campus - Laurentian University, Medical Officer of Health, Algoma Public Health 4. Public Health and Preventive Medicine Post Graduate Program, Northern Ontario School of Medicine, East Campus - Laurentian University, Health Sciences Education Resource Centre 5. Health Sciences Librarian, Northern Ontario School of Medicine, Lakehead University Campus

$\square$ Corresponding author: Ian Arra, ian.arra@nosm.ca

Disclosures can be found in Additional Information at the end of the article

\section{Abstract}

Background and Objectives: The proximity of wind turbines to residential areas has been associated with a higher level of complaints compared to the general population. The study objective was to search the literature investigating whether an association between wind turbines and human distress exists.

Methods: A systematic search of the following databases (EMBASE, PubMed, OvidMedline, PsycINFO, The Cochrane Library, SIGLE, and Scirus) and screening for duplication led to the identification of 154 studies. Abstract and full article reviews of these studies led to the identification of 18 studies that were eligible for inclusion as they examined the association of wind turbines and human distress published in peer-review journals in English between 20032013. Outcome measures, including First Author, Year of Publication, Journal Name, Country of Study, Study Design, Sample Size, Response Rate, Level of Evidence, Level of Potential Bias, and Outcome Measures of Study, were captured for all studies. After data extraction, each study was analyzed to identify the two primary outcomes: Quality of Study and Conclusion of Study Effect.

Results: All peer-reviewed studies captured in our review found an association between wind turbines and human distress. These studies had levels of evidence of four and five. Two studies showed a dose-response relationship between distance from wind turbines and distress, and none of them concluded no association.

Received 04/03/2014

Review began 04/06/2014

Review ended 05/22/2014

Published 05/23/2014

C) Copyright 2014

Arra et al. This is an open access article distributed under the terms of the Creative Commons Attribution License CC-BY 3.0., which permits unrestricted use, distribution, and reproduction in any medium, provided the original author and source are credited.
Conclusions: In this review, we have demonstrated the presence of reasonable evidence (Level Four and Five) that an association exists between wind turbines and distress in humans. The existence of a dose-response relationship (between distance from wind turbines and distress) and the consistency of association across studies found in the scientific literature argues for the credibility of this association. Future research in this area is warranted as to whether or not a causal relationship exists.

Categories: Otolaryngology, Preventive Medicine, Epidemiology/Public Health Keywords: systematic review, wind turbine, wind farm, wind power, human distress, noise, sound, 
infrasound, low-frequency, acoustic

\section{Introduction}

Unlike most industries, the global wind industry grows annually by $21 \%$ despite the recent economic challenges. Canada is the ninth largest producer of wind energy in the world with a 45 -fold growth in the industry in the year 2012 relative to 2000 [1-2].

The invention of the wind turbine as an electricity generating machine dates back to 1887 by James Blyth, a Scottish academic, and it used to light his holiday home in Marykirk, Scotland [3]. Wind turbines were at first welcomed by the public as being a source of energy that is both renewable and carbon emission-free. The need to generate electrical power on a large scale was the main driver in establishing the industrial wind turbines (IWTs) [4].

Wind turbines can be located as solo wind or in groups called "Wind Farms". In either form and for various reasons (e.g., minimizing transmission costs), wind turbines are usually positioned in close proximity to residential areas (farms, villages, towns, and cities). This proximity to residential areas has been associated with a higher level of complaints compared to the general population [5]. These complaints are coined in research conducted and articles written on the subject under different terms, such as "Extreme Annoyance", "Wind Turbine Syndrome (WTS)", and "Distress", among others. In this article, the term "distress" will be used unless we are quoting other articles.

Complaints resulting from the proximity to wind turbines vary in their nature, and distress is often attributed to different mechanisms, such as noise, visual impact, sleep disturbance, infrasound, and others [5-7]. Noise is the complaint that has been studied most often, especially given that environmental noise has become one of the major public health concerns of the 21st century [8].

These complaints triggered the debate about possible mechanisms of effect. Several hypothetical mechanisms have been suggested to explain the possible link(s) between wind turbines and the reported distress; some of these hypotheses attribute distress to one or more of the following: chronic noise exposure, infrasound effect, visual impact, perceived lack of control over noise, attitudes, personality, and age [5-6].

To assess the possible effects of wind turbines on human health, different outcome measures have been suggested, including annoyance, sleep disturbance, and cortisol levels. An alternative approach to health assessment involves the subjective appraisal of health-related quality of life, a concept that measures general well-being in all domains, including physical, psychological, and social domains [8].

Although the focus on researching mechanisms of effect may very well be a good first step to identifying the cause, finding an association is a cornerstone of establishing any causality, according to Hill's Criteria of Causality [9]. A key missing piece of the scientific literature is that of an up-to-date and thorough review that examines the possible existence of an association between wind turbine and human distress. Therefore, the objective of our study was to search the literature investigating whether or not an association between wind turbines and human distress exists.

\section{Materials And Methods}

\section{Study design}

A systematic review of the existing literature of published peer-reviewed studies investigating 
the association between wind turbines and human distress between January 2003 - January 2013 was undertaken. This study was conducted as a collaboration between the Northern Ontario School of Medicine (NOSM), Sudbury, and Grey Bruce Health Unit, Owen Sound, Ontario, Canada.

\section{Eligibility criteria}

Inclusion Criteria:

- Peer-reviewed studies

- Studies examining association between wind turbines and distress

- Studies published in peer-review journals

- English language

- Studies involving humans

- Studies published between January 2003 - January 2013

Exclusion Criteria:

- Non-English language reports

- Investigations reporting interim analysis that did not result in stopping the study

- Secondary and long-term update reports

- Duplicate reports

- Cost effectiveness and economic studies

- Engineering studies

- Studies involving animals

\section{Information sources}

The following bibliographic databases were searched: EMBASE, PubMed, Ovid Medline, PsycINFO and The Cochrane Library, SIGLE, and Scirus, the last two of which deal with grey literature (materials that cannot be found easily through conventional channels, such as publishers; for example, thesis, dissertations, and unpublished peer-reviewed studies). Authors who published multiple studies included in our review were also contacted to identify any additional studies.

\section{Search}

Two search approaches were taken: subject heading and keyword searching. Electronic keyword searches were conducted in EMBASE, PubMed, PsycINFO, The Cochrane Library, SIGLE, and Scirus for published peer-reviewed studies according to the study inclusion criteria. All search strategies included the same search terms and combinations ([Wind power OR wind 
farm OR air turbine OR wind turbine] AND [Distress OR annoyance, sleep disturbance, noise OR sound OR infrasound OR sonic OR low-frequency OR acoustic OR hear OR ear OR wind turbine syndrome]).

Appropriate subject headings and limiters were identified in consultation with the corresponding author and were used to conduct electronic searches in the following bibliographic databases: EMBASE, PsycINFO, Ovid Medline, and PubMed. In order to retrieve all relevant published studies, subject headings were exploded; select subject headings were also chosen as the major focus of the search. Searches were refined by setting a publication restriction of 2003 to current and limiting results to humans.

\section{Study selection}

Study selection was performed in three stages (Figure 1):

\section{Stage 1: Database Search}

The studies that were identified through the database subject heading search (194 studies), the keyword search (142), and other sources (13 studies) were screened for duplication, yielding 154 studies.

\section{Stage 2: Titles and Abstract Review}

Screening of the titles and abstracts of the 154 retrieved studies was conducted by one qualified reviewer (the first author) in order to exclude any obvious non-eligible studies. Of these, 40 studies were deemed eligible for inclusion in a full article review.

\section{Stage 3: Full Article Review}

Two qualified reviewers conducted a full article review of the 40 studies. This review had two goals: first, to exclude any studies of non-eligible trials; second, to extract data on specific variables for further analyses. Of the 40 studies, 18 studies were deemed eligible for inclusion in our analysis. 


\section{Cureus}

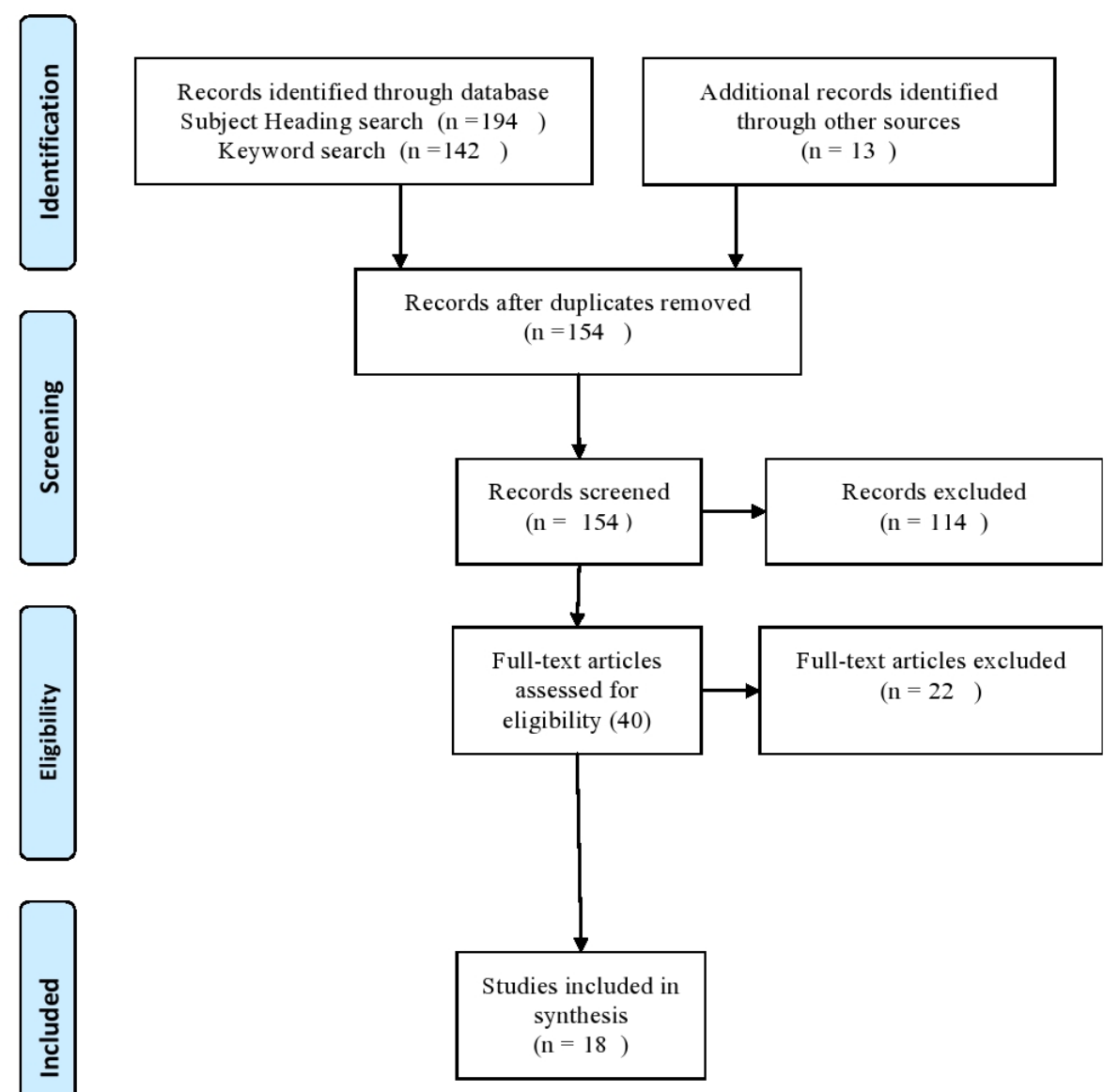

\section{FIGURE 1: Flowchart of the Review Screening Process}

Eighteen peer-reviewed studies published between January 2003 - January 2013 investigating the association between wind turbines and human distress were eligible for inclusion in the analysis after full article review publications.

\section{Data collection process}

Data extraction was conducted by a qualified reviewer (the first author) during the full article review of the 18 included studies. The source of data in the individual studies was confirmed by contacting investigators who authored multiple studies included in the review, due to the aggregated weight of these studies potentially affecting our conclusion. The confirmation aimed to verify whether the data examined in the individual studies were collected from a single population and used in more than one study, or from different independent populations.

\section{Data items}

Primary Outcomes:

- Quality of Study: The quality of the study was categorized into three groups (Low, Moderate, High) (categorical variable) 
- Conclusion of Study Effect: (whether the study concluded association of wind turbines with the effect on human health that was under investigation) (binary variable)

Variables (Outcome Measures of Individual Studies):

- First Author: The name of the first author (nominal variable)

- Year of Publication: The year in which the study was published (ordinal variable)

- Journal Name: The name of the publishing journal (nominal variable)

- Country of Study: The name of the country where the trial was originated (nominal variable)

- Study Design: The design of the study (nominal variable)

- Sample Size: The study sample size (continuous variable)

- Response Rate: The response rate of subjects in the study (continuous variable)

- Level of Evidence: The Level of evidence of the study (nominal variable)

- Level of Potential Bias: The level of risk of bias. Categorized into three groups according to Cochrane's recommendations [10]. (Low risk of bias: Plausible bias unlikely to seriously alter the results; Unclear risk of bias: Plausible bias that raises some doubt about the results; High risk of bias: Plausible bias that seriously weakens confidence in the results) (categorical variable)

- Outcome Measures of Study: The outcome measure under investigation in the study (nominal variable); these outcome measures are:

- Annoyance (Sensitivity to Noise)

- Sleep disturbance

- Visual impact

- Well-being (Quality of Life/Mental Effect)

- Dose-response (description of the change in distress caused by differing distances from a wind turbine)

- Infrasound effect

- Existing background noise (comparison of stress associated with wind turbines to stress associated with road traffic noise/quiet rural environment)

- Attitude to wind turbines (whether people who complain have negative personal opinions toward wind turbines)

- Economical benefit (whether people who benefit economically from wind turbines have a decreased risk of distress) 


\section{Risk of bias in individual studies}

Assessing the risk of bias of individual studies was performed at both the study level (study design, sample size, response rate, direction and magnitude of any potential bias and how it was handled, limitations, and reporting quality) and the outcome level (a cautious overall interpretation was drawn of the study's conclusions, whether effect of human distress exists, considering the specific study's objectives).

\section{Summary measures and synthesis of results}

After data extraction, each study was analyzed to identify the two primary outcomes: First, quality of study, taking into account the study's principle outcome measures; all outcomes, exposures, predictors, potential confounders, and effect modifiers; how the study size was arrived at; how quantitative variables were handled in the analyses; description of all statistical methods; and how loss to follow-up and missing data were addressed. Second, conclusion of study effect as a cautious overall interpretation of the study's conclusions, taking into account the specific study's objectives and how well these conclusions were supported by the study results.

\section{Risk of bias across studies}

To reduce potential sampling bias (for example, the quality of study could be confounded by journal name and name of first author), the reviewers blinded themselves to the name of the journal and authors until all data on the other variables of interest were collected. To reduce potential measurement bias, the following three measures were undertaken: The data were directly entered into the database instead of using collection forms, quality assurance on all steps of data collection and management was performed, and in any case of uncertainty in deciding the quality of study, the reviewer consulted one of our senior authors to confirm the decision. Furthermore, the source of data was confirmed by contacting investigators who authored multiple studies included in the review, due to the weight their aggregated studies would have in affecting our conclusions.

\section{Ethics approval}

This study used previously published data making it exempt from institutional ethics board approval.

\section{Results}

\section{Study selection}

Figure 1 presents a flowchart depicting the study screening process. The database searches produced 154 publications. From this group, 40 publications were eligible following screening the titles and abstracts. From this group, 18 publications were eligible for inclusion after full article review. These 18 studies, shown in Table 1, consist of six original studies and 12 nonoriginal studies (secondary analyses and literature reviews based on some of these original studies). Only the six original studies were included in the final analysis shown in Table 2 . The 12 non-original studies were excluded from the analysis to minimize potential bias associated with repeated results.

This review used previously published data; therefore, there was no missing data for any of the variables of interest.

\section{Study Characteristics}




\section{Cureus}

\begin{tabular}{|c|c|c|c|c|c|c|c|}
\hline $\begin{array}{l}\text { 1st Author, } \\
\text { Year }\end{array}$ & Country & Design & $\begin{array}{l}\text { Sample } \\
\text { Size }\end{array}$ & $\begin{array}{l}\text { Response } \\
\text { Rate \% }\end{array}$ & $\begin{array}{l}\text { Level of } \\
\text { Evidence }\end{array}$ & $\begin{array}{l}\text { Risk Of Bias } \\
\text { Within Studies }\end{array}$ & $\begin{array}{l}\text { Quality of } \\
\text { Study }\end{array}$ \\
\hline $\begin{array}{l}\text { Bakker [11] } \\
2012^{\wedge}\end{array}$ & Netherlands & Cross-sectional & 725 & 37 & 4 & $\begin{array}{l}\text { Unclear risk of } \\
\text { bias }\end{array}$ & Moderate \\
\hline $\begin{array}{l}\text { Hanning [12] } \\
2012^{\wedge}\end{array}$ & UK & $\begin{array}{l}\text { Expert } \\
\text { Opinion/Review }\end{array}$ & N/A & N/A & 5 & $\begin{array}{l}\text { Unclear risk of } \\
\text { bias }\end{array}$ & Moderate \\
\hline $\begin{array}{l}\text { Nissenbaum } \\
\text { [13] } 2012 ¥\end{array}$ & USA & Cross-sectional & 106 & 75 & 4 & Low risk of bias & Moderate \\
\hline $\begin{array}{l}\text { Knopper [6] } \\
2011 \wedge\end{array}$ & Canada & Review & 15 & N/A & 4 & $\begin{array}{l}\text { Unclear risk of } \\
\text { bias }\end{array}$ & High \\
\hline $\begin{array}{l}\text { Shepherd [14] } \\
2011 ¥\end{array}$ & $\begin{array}{l}\text { New } \\
\text { Zealand }\end{array}$ & Cross-sectional & 39,158 & 34,32 & 3,4 & Low risk of bias & High \\
\hline $\begin{array}{l}\text { Janssen [15] } \\
201 \wedge^{\wedge}\end{array}$ & Netherlands & $\begin{array}{l}\text { Secondary } \\
\text { analysis }\end{array}$ & 1820 & $\begin{array}{l}68,58 \\
<30\end{array}$ & 4 & Low risk of bias & High \\
\hline $\begin{array}{l}\text { Pedersen [16] } \\
201 \wedge^{\wedge}\end{array}$ & Sweden & $\begin{array}{l}\text { Secondary } \\
\text { analysis }\end{array}$ & 1755 & * & 4 & Low risk of bias & High \\
\hline $\begin{array}{l}\text { Bolin [17] } 2011 \\
\wedge\end{array}$ & Sweden & Review & N/A & N/A & 4 & $\begin{array}{l}\text { Unclear risk of } \\
\text { bias }\end{array}$ & Low \\
\hline $\begin{array}{l}\text { Pedersen [18] } \\
2010^{\wedge}\end{array}$ & Sweden & $\begin{array}{l}\text { Secondary } \\
\text { analysis }\end{array}$ & 725 & 37 & 4 & Low risk of bias & High \\
\hline Salt [7] $2010 ¥$ & USA & $\begin{array}{l}\text { Expert Opinion } \\
\text { Report }\end{array}$ & N/A & N/A & 5 & $\begin{array}{l}\text { Unclear risk of } \\
\text { bias }\end{array}$ & High \\
\hline $\begin{array}{l}\text { Pedersen [19] } \\
2009 ¥\end{array}$ & Netherlands & Cross-sectional & 1948 & 37 & 4 & Low risk of bias & High \\
\hline $\begin{array}{l}\text { Keith [20] } 2008 \\
\wedge\end{array}$ & Canada & Expert Review & N/A & N/A & 5 & $\begin{array}{l}\text { Unclear risk of } \\
\text { bias }\end{array}$ & High \\
\hline $\begin{array}{l}\text { Pedersen [21] } \\
2008^{\wedge}\end{array}$ & Sweden & $\begin{array}{l}\text { Secondary } \\
\text { analysis }\end{array}$ & 1095 & N/A & 4 & Low risk of bias & High \\
\hline $\begin{array}{l}\text { Pedersen [22] } \\
2008^{\wedge}\end{array}$ & Sweden & $\begin{array}{l}\text { Secondary } \\
\text { analysis }\end{array}$ & 1822 & 60 & 4 & Low risk of bias & High \\
\hline $\begin{array}{l}\text { Pedersen [23] } \\
200 \wedge^{\wedge}\end{array}$ & Sweden & $\begin{array}{l}\text { Qualitative } \\
\text { Study }\end{array}$ & 15 & N/A & 5 & Low risk of bias & High \\
\hline $\begin{array}{l}\text { Pedersen [5] } \\
2007 ¥\end{array}$ & Sweden & Cross-sectional & 754 & 58 & 4 & Low risk of bias & High \\
\hline $\begin{array}{l}\text { Leventhall [24] } \\
2006^{\wedge}\end{array}$ & UK & Report & N/A & N/A & 5 & $\begin{array}{l}\text { Unclear risk of } \\
\text { bias }\end{array}$ & High \\
\hline $\begin{array}{l}\text { Pedersen [25] } \\
2004 ¥\end{array}$ & Sweden & Cross-sectional & 351 & 68 & 4 & Low risk of bias & High \\
\hline
\end{tabular}




\section{Cureus}

\section{TABLE 1: Study Characteristics of 18 Peer-reviewed Studies Published between January 2003 - January 2013 Investigating the Association between Wind Turbines and Human Distress}

N/A = Not applicable $; ¥=$ Original Study; ${ }^{\wedge}=$ Secondary Article (some studies have generated several articles, so the findings in these article were repeats of the findings in the original study) ; ${ }^{*}=$ Data not available; High = Available data indicates high quality; Moderate = Available data indicates moderate quality; Low = Available data indicates low quality; High risk of bias: Plausible bias that seriously weakens confidence in the results; Unclear risk of bias: Plausible bias that raises some doubt about the results; Low risk of bias: Plausible bias unlikely to seriously alter the results.

\begin{tabular}{|c|c|c|c|c|c|c|c|c|c|}
\hline $\begin{array}{l}\text { 1st Author, } \\
\text { Year }\end{array}$ & $\begin{array}{l}\text { Does- } \\
\text { response }\end{array}$ & $\begin{array}{l}\text { Road Traffic } \\
\text { Noise / quiet rural } \\
\text { environment }\end{array}$ & $\begin{array}{l}\text { Sleep } \\
\text { Disturbance }\end{array}$ & $\begin{array}{l}\text { Annoyance/ } \\
\text { sensitivity to } \\
\text { noise }\end{array}$ & $\begin{array}{l}\text { Visual } \\
\text { impact }\end{array}$ & $\begin{array}{l}\text { Attitude to } \\
\text { wind } \\
\text { turbines }\end{array}$ & $\begin{array}{l}\text { Infrasound } \\
\text { effect }\end{array}$ & $\begin{array}{l}\text { Well-being } \\
\text { (Quality of } \\
\text { Life / mental } \\
\text { effect) }\end{array}$ & $\begin{array}{l}\text { Economical } \\
\text { Benefit }\end{array}$ \\
\hline $\begin{array}{l}\text { Nissenbaum } \\
\text { [13] } 2012\end{array}$ & $p<0.05$ & & $p=0.03$ & & & & & $p=0.002$ & \\
\hline Shepherd & & & $U-R=0.43 p$ & $U-R=0.44 p$ & & & & U-R $=0.20 p<$ & \\
\hline [14] 2011 & & & $<0.001$ & $<0.001$ & & & & 0.01 & \\
\hline Salt [7] 2010 & & & & Exp & & & $\operatorname{Exp}$ & & \\
\hline $\begin{array}{l}\text { Pedersen } \\
\text { [19] } 2009\end{array}$ & $\begin{array}{l}\text { LRC }= \\
0.50 p< \\
0.001\end{array}$ & $\begin{array}{l}\text { LRC }=1.07-p< \\
0.01\end{array}$ & & $\begin{array}{l}\text { LRC }=0.35 p \\
<0.001\end{array}$ & $\begin{array}{l}\text { LRC }=1.04 \\
p<0.001\end{array}$ & $\begin{array}{l}\text { LRC }=0.54 \\
p<0.001\end{array}$ & & & $\begin{array}{l}\text { LRC }=-2.77 \\
p<0.001\end{array}$ \\
\hline $\begin{array}{l}\text { Pedersen [5] } \\
2007\end{array}$ & & $\begin{array}{l}\mathrm{OR}=1.1(95 \% \mathrm{Cl} \\
0.91 \text { to } 1.21)\end{array}$ & & $\begin{array}{l}\mathrm{OR}=1.1 \\
(95 \% \mathrm{Cl} 1.01 \\
\text { to } 1.25)\end{array}$ & $\begin{array}{l}\mathrm{OR}=1.1 \\
(95 \% \mathrm{Cl} \\
0.97 \text { to } \\
1.21)\end{array}$ & $\begin{array}{l}\mathrm{OR}=1.1 \\
(95 \% \mathrm{Cl} \\
1.00 \text { to } \\
1.25)\end{array}$ & & & \\
\hline $\begin{array}{l}\text { Pedersen } \\
\text { [25] } 2004\end{array}$ & & & $\begin{array}{l}\mathrm{Rs}=0.35 \mathrm{p} \\
<0.001\end{array}$ & $\begin{array}{l}\mathrm{Rs}=0.42 \mathrm{p} \\
<0.001\end{array}$ & $\begin{array}{l}\mathrm{Rs}=0.52 \mathrm{p} \\
<0.001\end{array}$ & $\begin{array}{l}\mathrm{Rs}=0.33 \mathrm{p} \\
<0.001\end{array}$ & & & \\
\hline
\end{tabular}

TABLE 2: Outcome Measures of Six Peer-reviewed Original Studies Published between January 2003 - January 2013 Investigating the Association between Wind Turbines and Human Distress

Rs = R-squared for the model; U-R: Unadjusted $r ; p=p$-value; LRC = logistic regression coefficients; Exp = Expert Opinion Report

\section{Study characteristics and risk of bias within studies}

Table 1 shows data on the 18 peer-reviewed studies captured in our review, including individual study characteristics, level of potential bias, and quality of study.

\section{Results of individual studies}

Table 2 shows summary data on the six original studies' objectives, $p$-values, and outcome 
measures.

\section{Risk of bias across studies}

One main source of potential bias across these studies was that 10 of them, listed below, were mainly based on three data sets. The first data set (SWE00) was collected in Sweden in the year 2000 in agricultural areas, the second (SWE05) was collected in different environments in Sweden 2005, and the third (NL07) was collected all over the Netherlands in 2007. This potential bias was eliminated by using only the three original studies that collected the data sets $[5,19,25]$. The rest of the 10 studies (non-original studies) were excluded from the analysis to avoid repeated results.

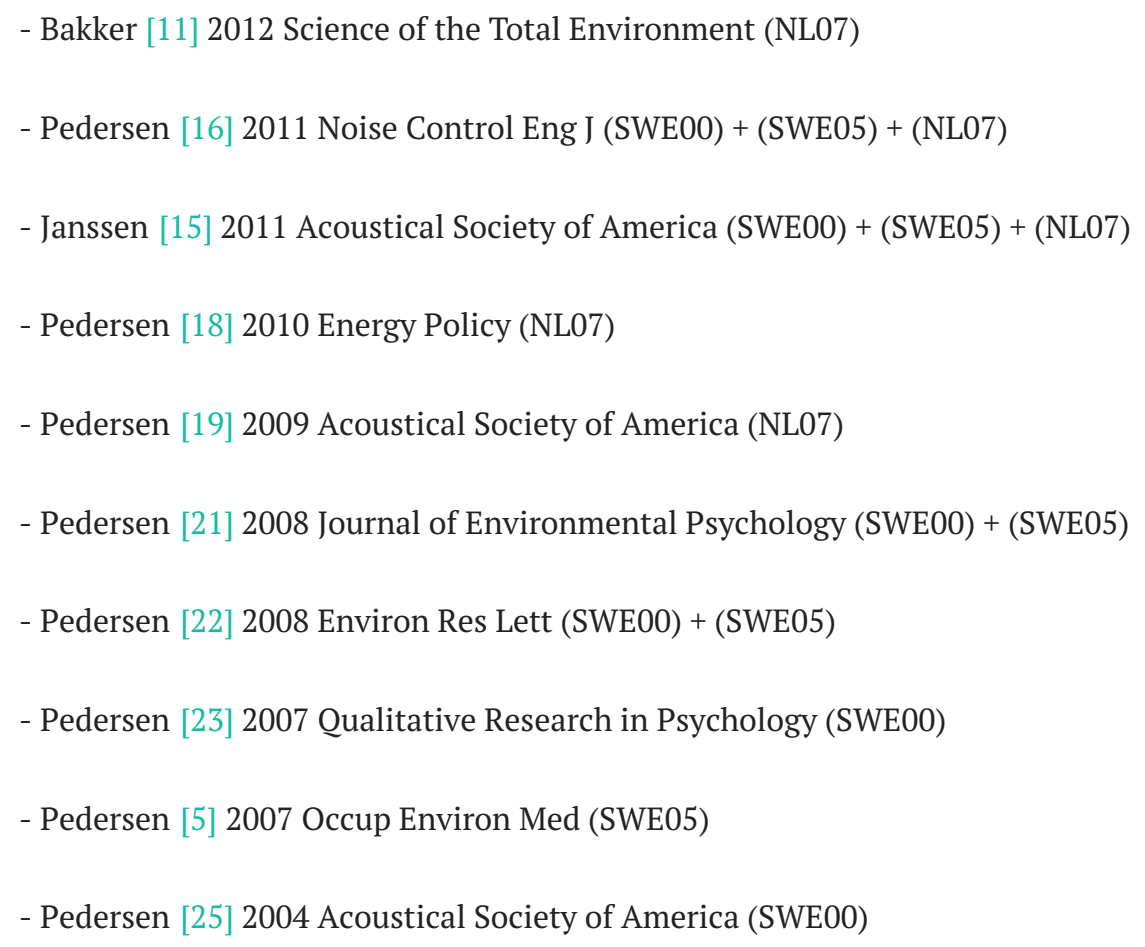
17].

\section{Key results}

- All 18 peer-reviewed studies captured in our review found an association between wind turbines and one or more types of human distress. These studies had a level of evidence of four and five.

- None of the studies captured in our review found any association (potential publication bias).

- These studies were published in a variety of journals (representative sample).

- Two of these studies showed a dose-response relationship between distance from wind turbines and distress (Table 2).

- There is still no evidence of whether or not a causal relationship between distance from wind turbines and distress exists. 


\section{Discussion}

\section{Summary of evidence}

The peer-reviewed studies we reviewed provide reasonable evidence (Levels Four and Five) that an association exists between wind turbines and distress in humans.

Two of these studies showed a dose-response relationship between distance from wind turbines and distress, and none of the 18 studies concluded no association (consistency of association). The existence of a dose-response relationship and consistency, two of the Hill's Criteria of Causality, argues for the credibility of the association.

All the evidence comes from expert opinion, case studies, and cross-sectional studies. No higher level of evidence observational studies, namely case-control and cohort studies, were utilized to investigate the subject. For example, although Shepherd, et al's study [14] had a sound design and was well conducted and reported, it is considered at a lower level of evidence as a cross-sectional study has an increased potential for bias of its results.

Although three of the studies [6-7, 24] suggested that low-frequency sound energy wind turbines (i.e., infrasound below $20 \mathrm{~Hz}$ ) may directly and negatively affect health, the level of evidence for these studies is also weak (expert opinions [7, 24] and a review [6] citing these two studies).

Economic benefit found in two of the studies $[15,19]$ could be intuitively and prematurely viewed as a factor lowering the credibility of the complaint. However, in our opinion, compensation would have lowered the credibility of the complaint only if these people had no distress following compensation. People in the studies who benefited economically from wind turbines had a decreased risk of distress but not a complete elimination of distress. Furthermore, the fact that the level of distress could be altered with financial compensation only speaks to the existence of distress.

It is worth pointing out that no causality has been established. The distress could be due to factors other than actual noise exposure. For example, the distress experienced by the participants in the original studies may have been generated or exaggerated by exposure to negative opinions on wind turbine.

\section{Limitations}

This study has a number of limitations and sources of bias. One source of bias is the exclusion of non-English studies. For example, China is the world's leading country in the number of wind turbines [1]. The exclusion of non-English studies might have affected the overall conclusions of our review.

Another source of bias is the fact that the reviewer could not be completely blinded to the journals' or authors' names. There might be a theoretical incline to give studies in high impact journals higher quality because of their reputation (potential sampling bias). Nevertheless, if this bias took place, it would have an effect on the magnitude of evidence and not on the existence of the association due to the dichotomous nature of this variable (the number of studies that speaks for an association will not change).

Publication bias could be the reason for the finding that none of the 18 peer-reviewed studies captured in our review found no association. However, potential publication bias was decreased by conducting a search in two major grey literature databases (SIGLE, and Scirus). 


\section{Generalizability}

The 18 studies were published in a variety of journals, making the captured studies a representative sample, which in turn increases our results' generalizability (external validity).

The fact that the data in two of the three mentioned data sets were collected in Sweden may decrease the external validity, but simultaneously may increase the internal validity following the above logic. Furthermore, although these data were collected from one country, it still would be a safe assumption that the people and their experience with wind turbines, on which these data were collected, are not fundamentally different from people and experiences in other countries.

\section{Future research}

Further research in the area of exposure assessment and measurement is needed. The mechanism and physiology of harm needs to be confirmed. There is a need to identify the actual risk of harm and the health outcomes in people exposed. Until research can separate out specific sets of significant factors for the exposure with higher-level evidence than is available now, our ability to mitigate the harm is limited. Possible future research could be conducting longitudinal studies, performing measurements before wind turbines and after, and observing what happens to people over time.

\section{Conclusions}

We have demonstrated in our review the presence of reasonable evidence (Levels Four and Five) supporting the existence of an association between wind turbines and distress in humans. The existence of a dose-response relationship between distance from wind turbines and distress as well as the consistency of association across studies found in the scientific literature argues for the credibility of this association. Future research in this area is warranted.

\section{Additional Information}

\section{Disclosures}

Human subjects: Consent was obtained by all participants in this study. This study used previously published data making it exempt from institutional ethics board approval. issued approval This study used previously published data making it exempt from institutional ethics board approval. Animal subjects: All authors have confirmed that this study did not involve animal subjects or tissue. Conflicts of interest: In compliance with the ICMJE uniform disclosure form, all authors declare the following: Payment/services info: All authors have declared that no financial support was received from any organization for the submitted work. Financial relationships: All authors have declared that they have no financial relationships at present or within the previous three years with any organizations that might have an interest in the submitted work. Other relationships: All authors have declared that there are no other relationships or activities that could appear to have influenced the submitted work.

\section{Acknowledgements}

Thank you, Andrea M. Davison, for assisting with the preparation of this manuscript.

\section{References}

1. The Global Wind Energy Council . Accessed: October 30, 2013: http://www.gwec.net/? $s=$ canada.

2. The Global Wind Energy Council. . (2012). Accessed: October 30, 2013: 
http://www.gwec.net/wp-content/uploads/2012/06/Top-10-Cumulative-Capacity-December2012.jpg.

3. University of Strathclyde Archives. Accessed: January 20, 2014:

http://stratharchives.tumblr.com/post/85511105886/week-18-windmill-designed-and-builtby-james.

4. Krogh C, Gillis L, Kouwen N, Aramini J: WindVOiCe, a self-reporting survey: adverse health effects, industrial wind turbines, and the need for vigilance monitoring. Bull Sci Technol Soc. 2011, 31:334-45.

5. Pedersen E, Hallberg L, Waye KP: Living in the vicinity of wind turbines--a grounded theory study. Qualitative Research in Psychology. 2007, 4:49-63.

6. Knopper LD, Ollson CA: Health effects and wind turbines: A review of the literature . Environ Health. 2011, 10:78. 10.1186/1476-069X-10-78

7. Salt AN, Hullar TE: Responses of the ear to low frequency sounds, infrasound and wind turbines. Hear Res. 2010, 268:12-21. 10.1016/j.heares.2010.06.007

8. World Health Organisation: Night noise guidelines for Europe. (2009). Accessed: October 30, 2013: http://www.euro.who.int/_data/assets/pdf_file/0017/43316/E92845.pdf.

9. Hill AB: The Environment and Disease: Association or Causation? . Proc R Soc Med. 1965, 58:295-300.

10. Higgins JPT, Altman DG, Sterne JAC on behalf of the Cochrane Statistical Methods Group and the Cochrane Bias Methods Group: Chapter 8: Assessing risk of bias in included studies. Cochrane Handbook for Systematic Reviews of Interventions. 2011, Version 5.1.0:Accessed: October 30, 2013: http://handbook.cochrane.org/chapter_8/8_assessing_risk_of_bias_in_included_studies.htm.

11. Bakker RH, Pedersen E, van den Berg GP, Stewart RE, Lok W, Bouma J: Impact of wind turbine sound on annoyance, self-reported sleep disturbance and psychological distress. Sci Total Environ. 2012, 425:42-51. 10.1016/j.scitotenv.2012.03.005

12. Hanning CD, Evans A: Wind turbine noise. BMJ. 2012, 344:e1527. 10.1136/bmj.e1527

13. Nissenbaum MA, Aramini JJ, Hanning CD: Effects of industrial wind turbine noise on sleep and health. Noise Health. 2012, 14:237-43. 10.4103/1463-1741.102961

14. Shepherd D, McBride D, Welch D, Dirks KN, Hill EM: Evaluating the impact of wind turbine noise on health-related quality of life. Noise Health. 2011, 13:333-9. 10.4103/14631741.85502

15. Janssen SA, Vos H, Eisses AR, Pedersen E: A comparison between exposure-response relationships for wind turbine annoyance and annoyance due to other noise sources. J Acoust Soc Am. 2011, 130:3746-53. 10.1121/1.3653984

16. Pedersen E: Health aspects associated with wind turbine noise-Results from three field studies. Noise Control Eng J. 2011, 59:47-53.

17. Bolin K, Bluhm G, Eriksson G, Nilsson ME: Infrasound and low frequency noise from wind turbines: Exposure and health effects. Environ Res Lett. 2011, 6:1-6. 10.1088/17489326/6/3/035103

18. Pedersen E, van den Berg F, Bakker R, Bouma J: Can road traffic mask the sound from wind turbines? Response to wind turbine sound at different levels of road traffic. Energy Policy. 2010, 38:2520-2527. 10.1016/j.enpol.2010.01.001

19. Pedersen E, van den Berg F, Bakker R, Bouma J: Response to noise from modern wind farms in The Netherlands. J Acoust Soc Am. 2009, 126:634-43. 10.1121/1.3160293

20. Keith SE, Michaud DS, Bly SHP: A proposal for evaluating the potential health effects of wind turbine noise for projects under the Canadian Environmental Assessment Act. Low Freq Noise Vib Active Control. 2008, 27:253-65.

21. Pedersen E, Larsman P: The impact of visual factors on noise annoyance among people living in the vicinity of wind turbines. J Environ Psychol. 2008, 28:379-89.

10.1016/j.jenvp.2008.02.009

22. Pedersen E, Waye KP: Wind turbines - low level noise sources interfering with restoration? . Environ Res Lett. 2008, 3:1-5.

23. Pedersen E, Waye KP: Wind turbine noise, annoyance and self-reported health and well-being in different living environments. Occup Environ Med. 2007, 64:480-6.

24. Leventhall HG: Low frequency noise and annoyance. Noise Health. 2004, 6:59-72.

25. Pedersen E, Waye KP: Perception and annoyance due to wind turbine noise--a dose-response relationship. J Acoust Soc Am. 2004, 116:3460-70. 